\title{
Penyuluhan Pemanfaatan Buah Ciplukan Sebagai Bahan Makanan Sehat Melalui Metode Jaga Jarak Fisik Akibat Wabah Covid 19
}

\author{
Tajidan*, Arifuddin Sahidu, Suparmin \\ Program Pascasarjana, Universitas Mataram, Mataram, Indonesia \\ Jl. Majapahit No.62, Mataram 83125, Indonesia.
}

Article history

Received: 20-05-2020

Revised: 22-05-2002

Accepted: 06-06-2020

*Corresponding Author:

Tajidan

Program Pascasarjana,

Universitas Mataram, Mataram,

Indonesia;

e-mail: tajidan@unram.ac.id

\begin{abstract}
In the situation of maintaining physical distance today requires all parties to innovate in carrying out activities including community service activities. The face to face method that has become a habit has to be changed by utilizing social media. One of the most widely used social media is WharsApp. In the context of disseminating information about the content and efficacy of ciplukan fruits, counseling was carried out using the physical distance keeping method through WhatsApp media. The results achieved from the implementation of counseling using social media WhatApp is increasing pesrta knowledge about the content and efficacy of ciplukan fruit respectively from $33.7 \%$ to $96.7 \%$ and from $53.3 \%$ to $86.7 \%$, and increased interest in consuming fruit ciplukan from $67.9 \%$ to $93.3 \%$.
\end{abstract}

Keywords: chlorogenic acid; fisalin; womb; efficacy; social media

Abtrak: Dalam situasi jaga jarak fisik dewasa ini mengharuskan semua pihak untuk berinovasi dalam melaksanakan kegiatan termasuk kegiatan pengabdian kepada masyarakat. Metode tatap muka langsung yang selama ini telah menjadi kebiasaan harus diubah dengan memanfaatkan media sosial. Salah satu media sosial yang banyak digunakan adalah WharsApp. Dalam rangka penyebaran informsi tentang kandungan dan khasiat buah ciplukan, maka dilaksanakan penyuluhan menggunakan metode jaga jarak fisik melalui media WhatsApp. Hasil yang dicapai dari pelaksanaan penyululuhan menggunakan media sosial WhatApp adalah meningkatnya pengetahuan pesrta tentang kandungan dan khasiat buah ciplukan masing-masing dari $33,7 \%$ menjadi $96,7 \%$ dan dari $53,3 \%$ menjadi $86,7 \%$, serta meningkatnya minat mengkonsumsi buah ciplukan dari $67,9 \%$ menjadi $93,3 \%$.

Kata Kunci: chlorogenik acid; fisalin; kandungan; khasiat; media sosial

\section{PENDAHULUAN}

Tanaman ciplukan merupakan tanaman liar yang masih dianggap sebagai gulma oleh petani, sehingga keberadaannya semakin langka, sehingga tidak heran apabila buah ciplukan dijual dengan harga yang pantastis antara Rp 250.000 sampai dengan Rp 500.000 per kilogram (Muhlisin, 2019; Rachmawati, 2019). Tingganya harga buah ciplukan sebanding dengan hasiatnya bagi kesehatan tubuh manusia, yaitu sebagai bahan obat herbal tradisional. Buah ciplukan berhasiat sebagai obat gusi berdarah dan obat mual, sementara daunnya berhasiat sebagai obat bisul, borok dan peradangan kulit (Rachmawati, 2019). 
Hasiat yang terkandung pada tanaman ciplukan tidak terlepas dari kandungan yang ada pada buah dan daunnya. Buah ciplukan mengandung antioksidan cukup tinggi. Kandungan antioksidan yang ada dalam buah ciplukan adalah fenolik yang dapat mencegah kanker. Buah ciplukan kaya akan vitamin, diantaranya vitamin $\mathrm{A}$, vitamin $\mathrm{C}$, vitamin $\mathrm{D}$ dan vitamin $\mathrm{K}$. Vitamin A dapat menyehatkan mata, vitamin $\mathrm{C}$ memperbaiki metabolisme tubuh, vitamin $\mathrm{D}$ selain baik bagi tulang dan gigi, juga dapat mencegah penyakit degenarif, sementara vitamin $\mathrm{K}$ berhasiat dalam meningkakan kesehatan reproduksi (Rachmawati, 2019). Kandungan senyawa yang ada pada buah ciplukan selain vitamin tersebut adalah chlorogenik acid, asam sitrum, alaidic acid, dan fisalin. Juga mengandung asam malat, tanin, alkaloid, kriptoxantin, dan gula. Kandungan senyawa tersebut selain sebagai asupan energi bagi tubuh, juga dapat merawat tubuh agar tetap bugar serta menimbulkan rasa bahagia.

Mahany (2016) yang dikutip dari Brilio.net melaporkan bahwa terdapat 16 manfaat dari buah ciplukan, yaitu mengobati penyakit jantung, obat asma, obat tekanan darah, obat strok, obat kanker, obat kencing manis, serta berhasiat sebagai penjernih kencing, menurunkan deman, menghilangkan kuning pada bayi, menambah kecerdasan, menghilangkan sakit persendian, menurunkan kolesterol, menambah darah dan sebagai penawar racun.

Hasiat dan manfaat tanaman ciplukan yang demikian banyak sebagai mana disebutkan di atas, juga Deviana (2019) melaporkan manfaat paling penting dari buah ciplukan adalah kandungan polifenol yang dapat menetralkan radikal bebas dalam tubuh, sekaligus melindungi tubuh dari berbagai penyakit degeneratif. Kandungan antioksidan yang tinggi, sehingga dipercaya sebagai suplemen nutrisi yang ideal bagi kesehatan tubuh manusia, maka tidak mengherankan apabila memiliki nilai ekonomi tinggi (Muhlisin, 2019) dan dapat menghasilkan nilai tambah bagi petani dan pera pelaku usaha dari hulu sampai hilir. Namun manfaat ekonomi tersebut belum dinikmati oleh petani karena belum dibudidayakan sebagaimana tanaman hortikultura pada umumnya. Selain karena belum adanya pengetahuan yang mendukung proses budidaya, juga belum tersedianya benih ciplukan.

Permasalahan kelangkaan benih merupakan permasalahan klasik yang selalu dihadapi oleh petani. Ketergantungan benih pada impor dan ketersediaan benih di pasar menjadi kendala peningkatan produksi. Tanaman ciplukan yang sudah tergolong langka, karena sebagai gulma atau tanaman pengganggu yang harus diberantas, sehingga sulit ditemukan di sawah sebagai tanaman liar. Dalam beberapa tahun terakhir, sejak tahun 2016, buah ciplukan dijual di mal dengan harga tinggi (Devina, 2019), maka tanaman ciplukan mulai dibudidayakan, namun petani pemula yang mencoba membudidayakannya terkendala karena ketiadaan benih.

Dari hasil survey pendahuluan diketahui bahwa 92,9\% pernah melihat buah ciplukan dan sudah mengkonsumsi 67,9\%, namun hanya 35,7\% yang mengetahui bahwa buah ciplukan mengandung senyawa chlorogenik yang berhasiat sebagai bagi kesehatan tubuh. Gambaran ini mengindikasikan bahwa pengetahuan masyrakat tentang manfaat buah ciplukan sebagai bahan makanan yang menunjang kesehatan tubuh manusia masih rendah, sehingga wajar apabila buah ciplukan belum menjadi kebutuhan bagi sebagian masyarakat untuk mengkonsumsinya secara rutin sebagai menu makanan atau minuman sehari-hari.

Maksud dilaksanakannya penyuluhan adalah untuk menyampaikan informasi tentang manfaat buah ciplukan dalam menunjang kesehatan tubuh manusia dengan menggunakan metode jaga jarak fisik (physical distancing), yaitu dengan menggunakan media WhatsApp. Adapun tujuan yang hendak dicapai dalam pelaksanaan kegiatan pengabdian ini adalah: menyampaikan kandungan dan hasiat buah ciplukan bagi pemeliharaan kesehatan dan peningkatkan mengetahuan kelompok sasaran akan manfaat buah ciplukan bagi peningkatan kesegaran tumbuh manusia. 


\section{METODE}

\section{Kelompok Sasaran}

Sebagai sasaran penyuluhan adalah kelompok melenial dengan usia antara 18 sampai dengan 40 tahun dengan occupasi mahasiswa, wiraswasta dan pekerja mandiri.

\section{Waktu Pelaksanaan}

Evaluasi awal dilaksanakan dari tanggal 8 sampai dengan 10 April 2020. Kegiatan penyuluhan dilaksanakan dalam periode physical distancing dari tanggal 11 sampai dengan 14 April 2020. Kegiatan evaluasi akhir dilaksanakan tanggal 15 April 2020.

3. Metode Pelaksanaan

Penyuluhan dilaksanakan dengan metode physical distancing. Materi penyuluhan tentang manfaat buah ciplukan bagi kesehatan tubuh manusia disebarkan melalui media sosial WhatsApp. Materi bersumber dari berbagai media on-line. Materi disharing hanya kepada peserta yang telah memberikan respon evaluasi awal. Untuk menarik minat kelompok sasaran dalam membaca dan memahami materi penyuluhan, maka dilakukan kues dengan memberikan hadiah pulsa kepada peserta yang menjawab dengan benar melalui interaktif diskusi.

4. Variabel Pengukuran Hasil Pelaksanaan Penyuluhan

Beberapa variabel yang digunakan sebagai pengukuran hasil pelaksanaan penyuluhan sebagai berikut:

4.1 Output

a. Pengetahuan tentang tanaman dan buah ciplukan

b. Pengetahuan kandungan dalam buah ciplukan

c. Pengetahuan khasiat buah ciplukan bagi peningkatan kesehatan dan kesegaran tubuh manusia

\subsection{Outcome}
a. Pengenalan tanaman dan buah ciplukan
b. Keinginan mengkonsumsi buah ciplukan
c. Hasrat membeli buah ciplukan
d. Keinginan membudidayakan tanaman ciplukan.

\section{Analisis Data}

Data kuantitatif dan kualitatif hasil pelaksanaan penyuluhan dianalisis menggunaan statistik deskriptif menggunakan tabel dan grafik yang dilengkapi dengan narasi. Untuk memperoleh hasil analisis yang mendalam, maka dilakukan pula analisis komparatif antar komponen dalam tabel mapun ekstenal komponen dalam variabel lainnnya.

\section{HASIL DAN PEMBAHASAN}

\section{Peserta Penyuluhan}

Jumlah peserta 30 orang. terdiri atas mahasiswa 90 persen dan wiraswasta 10\%, berusia antara 18 sd 32 tahun, berdomisili dalam wilayah Provinsi Nusa Tenggara Barat. Tingkat pendidikan cukup homogen, yaitu $80 \%$ berpendidikan Sekolah Lanjutan Atas (SMA \& SMK atau Madrasah Aliyah), sisanya sebanyak $20 \%$ berpendidikan tinggi atau Sarjana. Berdasarkan jenjang pendidikan tampak bahwa peserta memilki pendidikan yang cukup tinggi yaitu di atas pendidikan dasar. Dengan 
demikian, maka peserta memiliki kemampuan intelektual dalam menyerap pembelajaran melalui media literasi (Meliansari, 2017). Demikian juga dari aspek jenis akupasi peserta yang terdiri atas mahasiswa dan wiraswasta diyakini memiliki kemampuan menyerap informasi dengan lebih mudah melalui belajar mandiri.

\section{Pengetahuan tentang Tanaman dan Buah Ciplukan}

Tanaman ciplukan termasuk kelompok tanaman perdu dan berumur satu musim atau kurang dari 6 (enam) bulan. Dari hasil evaluasi, sedikit sekali dari peserta yang mengetahu bahwa tanaman ciplukan merupakan tanaman perdu. Dari 30 orang peserta penyuluhan on line, hanya $43 \%$ yang menjawab dengan benar bahwa tanaman ciplukan merupakan tanaman perdu. Ini memberi indikasi bahwa pengetahuan tentang tanaman ciplukan masih rendah bagi mahasiswa ataupun bagi peserta. Materi yang sudah diberikan secara on-line tampaknya tidak dibaca secara cermat, sehingga sebagian besar menjawab bahwa tanaman ciplukan merupakan tanaman tahunan. Hal yang patut diapresiasi bahwa $90 \%$ dari 30 orang peserta mengetahui bentuk buah ciplukan. Tampaknya peserta lebih familiar dengan buah ciplukan daripada tanaman ciplukan yang memang tanaman ciplukan semakin langka dijumpai di lahan atau ladang, karena sebagian lahan sawah ditanamai dengan padi, sementara tanaman ciplukan tumbuh sebagai gulma diantara tanaman kacang tanah, jagung, kedele atau tanaman palawija lainnya yang di tanam pada musim kemarau (Rachmawati, 2019).

\section{Pengetahuan tentang Kandungan Buah Ciplukan}

Peserta penyuluhan on line dapat dipastikan memiliki mengetahui tentang kandungan buah ciplukan setelah dilakukan evaluasi. Dari 30 orang peserta yang dievaluasi ternyata $96,7 \%$ telah mengetahui bahwa buah ciplukan itu mengandung chlrogenik acid dan fusalin, hanya 3,3\% yang tidak mengetahui kandungannya. Pengetahuan ini tentu diperoleh dari bahan bacaaan yang telah disebarkan sebelumnya kepada para peserta. Peningkatan pengetahuan ini sangat siginfikan bila dibandingkan sebelum penyuluhan yang mana hanya $35,7 \%$ yang mengetahui bahwa buah ciplukan mengandung senyawa chlorogenik acid yang berhasiat bagi kesehatan tubuh manusia. Peningkatan pengetahuan peserta hampir 3 (tiga) kali lebih tinggi setelah dilakukan penyuluhan on line. Hal yang menarik adalah pengetahuan tentang kandungan dan khasiat buah ciplukan tampak lebih mencolok bila dibandingkan dengan pengetahuan tentang tanaman ciplukan itu sendiri.

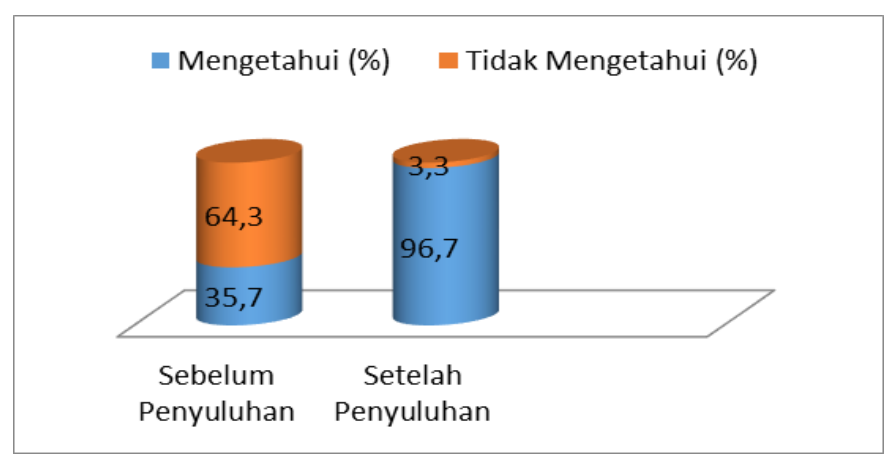

Gambar 1. Pengetahuan Peserta Penyuluhan tentang Kandungan Buah Ciplukan 


\section{Pengetahuan Tentang Khasiat Buah Ciplukan}

Seiring dengan pengetahuan akan kandungan buah ciplukan, maka pengetahuan tentang khasiat buah ciplukan memiliki hubungan yang linear, artimya ada hubungan yang positif antara pengetahuan tentang kandungan buah ciplukan dengan khasiat buah ciplikan bagi pemeliharaan kesehatan tubuh manusia.

Dari 30 peserta penyuluhan terdapat $86,7 \%$ yang mengetahui bahwa buah ciplukan berkhasiat sebagai antioksidan, yaitu zat berfungsi mereduksi radikal bebas dalam tubuh terutama dalam membersihkan radikan yang terbentuk akibat kerusakan sel tubuh melalui proses sekresi sel-sel mati dalam tumbuh. Peserta yang kurang paham akan khasiat buah ciplukan sebanyak 13,3\% yang menyatakan bahwa khasiat buah ciplukan adalah sebagai implamasi dan atau antiseptik. Dibadingkan sebelumnya bahwa 53,3\% dari peserta yang mengetahui khasiat buah ciplukan, artinya ada peningkatan pengetahuan sebesar 33,4\% antara sebelum penyuluhan dan setelah penyuluhan on line dilakukan. Penyuluhan menggunakan media on-line dinilai cukup baik dalam upaya meningkatkan pengetahuan peserta penyuluhan. Prasetya, et al (2019) dari hasil penelitiannya menympulkan bahwa penyuluhan kesehatan melalui media sosial mmberikan pengaruh terhadap pengetahuan dan sikap siswa dalam pemeliharaan kesehatan.

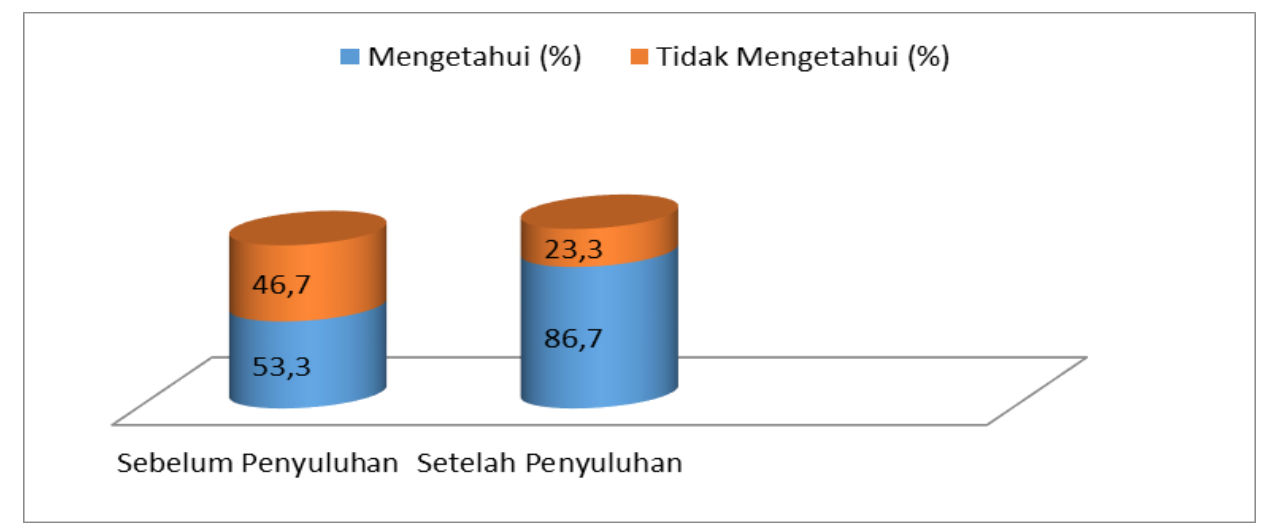

Gambar 2. Pengetahuan Peserta Penyuluhan tentang Khasiat Buah Ciplukan

Pengetahuan tentang khasiat buah ciplukan ini penting sebagai proses pendidikan non formal di kalangan mahasiswa dan para wiraswasta atau siapapun yang peduli bagi peningkatan derajat kesehatan tubuh manusia. Dengan pengetahuan akan khasiat buah ciplukan memberikan harapan akan potensi pasar dari buah ciplukan. Pengetahuan tentang khasiat buah ciplukan akan menumbuhkan kesadaran pentingnya mengkonsumsi buah ciplukan dalam bentuk buah segar atau setelah diolah menjadi jus, jeli, poding atau minumal fermentasi (Anonim, 2019).

\section{Efek Mengkonsumsi Buah Ciplukan Bagi Kesehatan Tubuh Manusia}

Separuh $(50 \%)$ dari jumlah peserta penyuluhan berpendapat bahwa mengkonsumsi buah ciplukan dapat melindungi dan memperbaiki kerusakan sel dalam tubuh manusia, sementara 26,7\% dapat melindungi tubuh dari penyakit kanker, dan $23,3 \%$ dari jumlh peserta berpendapat bahwa mengkonsumsi buah ciplukan dapat menyegarkan tubuh. Pendapat yang disampaikan oleh peserta penyuluhan tersebut mengindikasikan bahwa mereka telah mengetahui akan efek yang ditimbulkan apabila mengkonsumsi buah ciplukan, namun dalam kenyataannya bahwa sesungguhnya sebagian dari mereka yang pernah mengkonkumsi buah ciplukan, namun tak seorangpun yang mengkonsumsi buah 
ciplukan secara kontinyu. Oleh karena itu apa yang disampaikan masih sebatas ekspektasi (harapan). Perlu dilakukan pembuktian lebih lanjut akan kebenaran efek yang ditimbulkan apabila buah ciplukan dikonsumsi secara terus menerus.

\section{Minat Mengkonsumsi Buah Ciplukan}

Pengetahuan akan khasiat dan efek mengkonsumsi buah ciplukan bagi kesehatan tumbuh manusia akan berdampak pada sejauh mana minat peserta untuk mengkonsumsi buah ciplukan. Tampaknya dari 30 orang peserta penyuluhan on line, diantaranya 93,3\% yang menaruh minat untuk mengkonsumsi buah ciplukan, sementara $6,7 \%$ tidak berminat atau ragu-ragu. Suatu peningkatan yang signifikan dibandingkan dengan evaluasi awal sebelum dilakukan penyuluhan. Sebelum penyuluhan on line dilakukan terdapat $67,9 \%$ yang menyatakan pernah mengkonsumsi buah ciplukan. Ini memberikan petunjuk bahwa minat mengkonsumsi buah ciplukan meningkat setekah dilakukan penyuluhan on line, peningkatannya sebesar 25,4\%. Suatu peningkatan yang pantastis untuk diapresiasi, sebab penyuluhan dilakukan dengan metode jaga jarak fisik (physical distancing). Pemanfaatan teknologi jaringan (internet) dengan menggunakan aplikasi media social ternyata efektif dalam melaksanakan penyuluhan kepada kelompok sasaran.

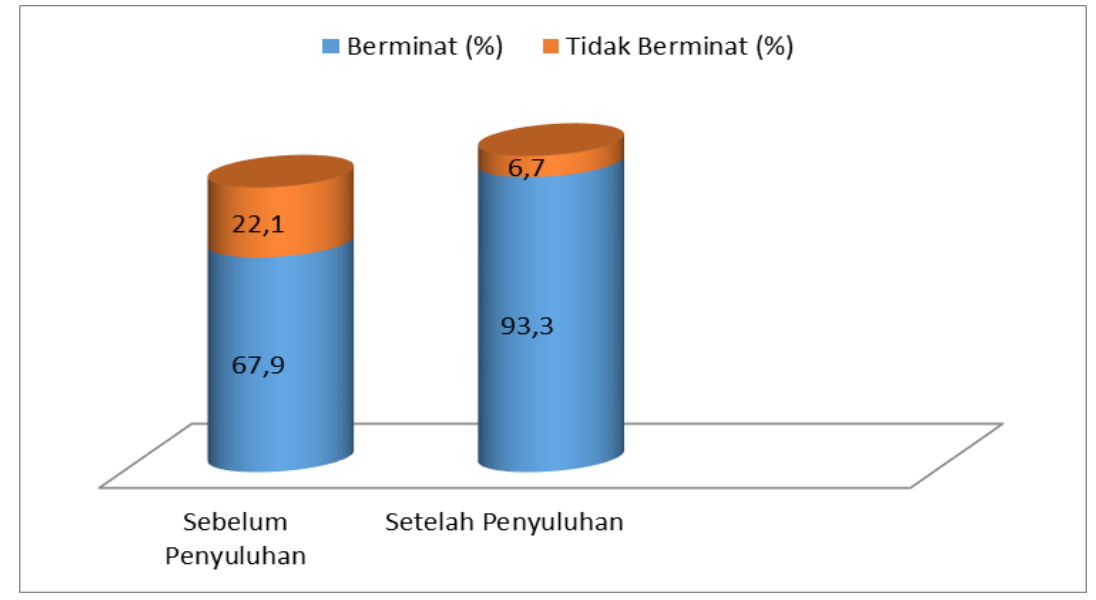

Gambar 3. Minat Peserta Mengkonsumsi Buah Ciplukan

Pelaksanaan penyuluhan melalui media sosial seperti WhatsApp diperlukan persyaratan atau kelengkapan berupa tersediana media komunikasi handphone berbasis android, tersedianya jaringan internet, dan tersedinya quota atau pulsa (Abay, 2018). Oleh karena itu ketersedian sarana dan prasarana sebagai mana disebutkan di atas harus mendapatkan perhatian. Penyuluhan menggunakan media sosial dengan sasaran petani tentu akan mendapat hambatan pada ketersediaan sarana komuniksi, karena belum semua petani memiliki handphone yang berbasis android.

\section{Minat Membeli Buah Ciplukan}

Hal yang cukup menarik adalah walau mereka mengetahui khasiat dan efek positif dari mengkonsumsi buah ciplukan, namun tidak seluruhnya berminat untuk membeli buah ciplukan. Sebagai gambaran dari 30 orang peserta penyuluhan terdapat $80 \%$ yang berminat untuk membeli sebagai solusi untuk mendapatkan buah ciplukan, sementara $20 \%$ lainnya tidak bersedia membelinya dan/atau ragu-ragu. 
Dari $93,3 \%$ yang berminat mengkonsumsi buah ciplukan sebagian diperoleh dengan cara mendapatkan secara cuma-cuma atau membudidayakannya. Potensi pasar bagi buah ciplukan tampak cukup besar, namun masih ada faktor koreksi berupa selera, terutama pada citra rasa dan aroma dan penampilan.

Pengolahan buah ciplukan menjadi jus, jeli, atau puding akan meningkatkan citra rara, serta meningkatkan selera dan minat calon pembeli (https://www.ngopibareng.id/timeline/buah-liarciplukan-diolah-jadi-jus-dan-puding-kaya-manfaat-678816). Aspek pengolahan menjadi tantangan bagi para pengusaha yang menaruh minat dalam menafaatkan potensi buah ciplukan agar dapat diterima oleh calon pembeli sebagai komoditas yang bernilai ekonomi.

\section{Minat Membudidayakan Tanaman Ciplukan}

Pengalaman membudidayakan tanaman ciplukan dari peserta sangat sedikit, yaitu 3,6\%, sisanya $(96,4 \%)$ belum pernah membudidayakannya. Gambaran ini membuktikan bahwa tanaman ciplukan belum mendapatkan perhatian di kalangan masyarakat pada umumnya, termasuk pemerintah belum gencar melakukan sosialisasi atau penyuluhan tentang budidaya tanaman ciplukan tersebut. Setelah dilakukan penyuluhan tampak bahwa minat peserta meningkat menjadi 83,3\%. Peningkatan minat mencapai 79,7\%. Peningkatan minat tersebut antara lain karena tertarik dengan kandungan dan khasiat buah ciplukan bagi kesehatan tumbuh manusia, di samping itu dampaknya pada peningkatan nilai ekonomi dari budidaya tanaman ciplukan yang diprediksi cukup sigininifikan sebagai salah satu sumber penghasilan.

Minat membudiayakan masih terkedala oleh berbagai faktor di antaranya adalah ketersediaan faktor produksi terutama adalah ketersediaan benih tanaman ciplukan, ketersediaan lahan, dan ketersedian tenaga kerjadan modal. Faktor-faktor produksi tersebut harus dikelola agar dapat disatukan dalam satu unit bisnis yang memungkinkan dilakukannya proses produksi agar dapat menghasilkan produk buah ciplukan (Anonim, 2018).

\section{Kesimpulan}

\section{KESIMPULAN DAN SARAN}

Pelaksanaan penyululuhan menggunakan media sosial WhatApp dapat meningkatnya pengetahuan peserta tentang kandungan dan khasiat buah ciplukan masing-masing dari 33,7\% menjadi 96,7\% dan dari $53,3 \%$ menjadi $86,7 \%$, serta meningkatnya minat mengkonsumsi buah ciplukan dari $67,9 \%$ menjadi 93,3\%.

\section{Saran}

Penyuluhan tentang kandungan dan hasiat buah ciplukan dengan sasaran para petani dan atau kelompok masyarakat lainnya sangat dianjurkan agar mereka tertarik untuk membudidayakan dan mengusahakan tanaman ciplukan sebagai sumber tambahan penghasilan. Perlu dilakukan pembuktian lebih lanjut akan kebenaran efek yang ditimbulkan apabila buah ciplukan dikonsumsi secara terus menerus.

\section{Ucapan Terima Kasih}

Terimakasih disampaikan kepada para peserta yang telah meluangkan waktunya untuk membaca materi yang telah disebarkan dan bersedia mengisi angket evaluasi awal dan evaluasi akhir. Terimakasih pula disampaikan kepada redaksi dan reviuwer yang telah berkenan menerbitkan artikel ini pada Jurnal GemaNgabdi. 


\section{DAFTAR PUSTAKA}

Abay, U., 2018. Penyuluhan Pertanian Melalui Media Sosial. http://www.swadayaonline.com/artikel/1434/Penyuluhan-Pertanian-Melalui-Media-Sosial/

Anonim, 2019. Buah Liar, Ciplukan Diolah Jadi Jus dan Puding Kaya Manfaat.

https://www.ngopibareng.id/timeline/buah-liar-ciplukan-diolah-jadi-jus-dan-puding-kayamanfaat-678816

Anonim, 2018. Cara Budidaya Ciplukan Jumbo Untuk Pemula. https://www.pertanianku..com

Deviana, I., 2019. Rupanya 8 Khasiat Ini Yang Bikin Buah Ciplukan Yang Kini Dijual Mahal. IDN Times. https://idntimes.com.

Meliansari, 2017. Hubungan Kemampuan Belajar Mandiri Dengan Hasil Mata Pelajaran PPKn di Paket C di Desa Woyono Kecamatan Gedung Tataan Kabupaten Pesawaran. FKIP Universitas Lampung. Bandar Lampung.

Mahany, 2016. 16 Maanfaat Buah Ciplukan. http://dinkes.sumutprov.go.id/v2/berita-371-16-manfaatbuah-cimplukan-.html

Muhlisin, A., 2019. Manfaat Daun dan Buah Ciplukan Beserta Efek Sampingnya. Honestdocs Editorial Team.www.honestdocs.id

Prasetya, AW., K.Rochadi, N. Lumongga, 2019. Pengaruh Media Sosial Dalam Peningkatan Pengetahuan dan Sikap Siswa SMA terhadap Pencegahan Stain Gigi. Jurnal Kesmas Jambi. Vol. 3 Nomor 1 September 2019.

Pratama, N, 2019. Manfaat Buah Ciplukan Yang Dulu Dicampakkan, Kini Diburu dan Harganya Selangit. Tribun Kaltim. https:kaltim.tribunmews.com.

Rachmawati, N., 2019. 20 Manfaat Buah Ciplukan Untuk Kesehatan Yang Jarang Diketahui. https://m.bola.com.

Seidle, M., 2019. What Is a Product Mix. Small Business: Type of Busniness to Start. Starting a Production Company. https://smallbusiness.chron.com.

Tajidan, FX Edy Fernandez, Halil, dan Efendy, 2019. Pendampingan Pembiayaan Pada Pengembangan Agroindustri VCO di Desa Sokong Kecamatan Tanjung. Program Studi Agribisnis, Jurusan Sosial Ekonomi, Fakultas Pertanian, Lembaga Penelitian dan Pengabdian Kepada Masyarakat Universitas Mataram.

Widiastuti, V., 2019. Dijual Mahal di Luar Negeri, Simak 7 Manfaat Buah Ciplukan Bagi Kesehatan. HEALTH/KONSULTASI. https:google.com. 